\title{
An Endolithic Microbial Community in Dolomite Rock in Central Switzerland: Characterization by Reflection Spectroscopy, Pigment Analyses, Scanning Electron Microscopy, and Laser Scanning Microscopy
}

\author{
T. Horath ${ }^{1}$, T.R. Neu ${ }^{2}$ and R. Bachofen ${ }^{1}$ \\ (1) Institute of Plant Biology/Microbiology, University of Zürich, Zollikerstrasse 107, CH-8008, Zürich, Switzerland \\ (2) Department of River Ecology, UFZ Center for Environmental Research, Leipzig-Halle, Brückstrasse 3A, D-39114 Magdeburg, Germany \\ Received: 22 March 2005 / Accepted: 22 March 2005 / Online Publication: 6 April 2006
}

\begin{abstract}
A community of endolithic microorganisms dominated by phototrophs was found as a distinct band a few millimeters below the surface of bare exposed dolomite rocks in the Piora Valley in the Alps. Using in situ reflectance spectroscopy, we detected chlorophyll $a$ (Chl a), phycobilins, carotenoids, and an unknown type of bacteriochlorophyll-like pigment absorbing in vivo at about $720 \mathrm{~nm}$. In cross sections, the data indicated a defined distribution of different groups of organisms perpendicular to the rock surface. High-performance liquid chromatography analyses of pigments extracted with organic solvents confirmed the presence of two types of bacteriochlorophylls besides chlorophylls and various carotenoids. Spherical organisms of varying sizes and small filaments were observed in situ with scanning electron microscopy and confocal laser scanning microscopy (one- and two-photon technique). The latter allowed visualization of the distribution of phototrophic microorganisms by the autofluorescence of their pigments within the rock. Coccoid cyanobacteria of various sizes predominated over filamentous ones. Application of fluorescence-labeled lectins demonstrated that most cyanobacteria were embedded in an exopolymeric matrix. Nucleic acid stains revealed a wide distribution of small heterotrophs. Some biological structures emitting a green autofluorescence remain to be identified.
\end{abstract}

Correspondence to: R. Bachofen; E-mail: bachofen@botinst.unizh.ch

\section{Introduction}

Endolithic phototrophic communities occur worldwide and are particularly important as pioneers in cold and hot dry habitats. In the Piora Valley, such organisms colonize bare dolomite rock and form a clearly defined layer a few millimeters below the rock surface. Studies of endolithic microorganisms started with Diels [7], who discovered this phenomenon in the Dolomites in Austria and Italy. Since then endoliths have been described in habitats like hot semiarid lands, rocks in streams, and hot and cold deserts (for recent reviews, see $[1,10,16$, 34, 38]). Endolithic populations are dominated by cyanobacteria and surprisingly, the endolithic cyanobacterial biomass is estimated to amount to $5-6 \%$ of the total global cyanobacterial biomass [15]. So far, most of our knowledge of endolithic microorganisms is restricted to oxygenic phototrophs (green algae and cyanobacteria) and fungi as partners of lichen symbiosis. Recently, endolithic populations have gained new interest because they may serve as a model of extraterrestrial life, e.g., life on Mars [20, 22].

Characterization and taxonomic determinations of endolithic organisms were done mainly by light and electron microscopy, and culturing. Only recently have new spectroscopic methods been introduced [29, 37], and molecular methods have been used rarely up to now $[5,30]$. In most investigations, the spatial arrangement of the endolithic population was not resolved, as the samples prepared from the rock average both horizontally and vertically.

The objectives of this work were (1) to determine the spatial heterogeneity of the phototrophic endolithic population and (2) to obtain information on its structure perpendicular to the rock surface by investigating the 
intact endolithic population in dolomite rock by analyzing the distribution of pigments and cells with in situ techniques, reflection spectroscopy, and confocal laser scanning microscopy [CLSM, and two-photon (2P)-LSM] .

\section{Methods}

Source of the Material. Dolomite rock was collected in the Piora Valley in the southern part of the Swiss Alps at an elevation of $1965 \mathrm{~m}$ a.s.l. The coordinates of the specific sampling site are $46^{\circ} 33^{\prime} \mathrm{N}, 8^{\circ} 43^{\prime} \mathrm{E}$ (Swiss coordinates, 698'100/155'950). The geology of the Piora Valley is characterized by a dolomite trough, oriented east-west and embedded with crystalline rock formations. Due to erosion, the dolomite is often not covered by vegetation and exposed to the atmosphere, forming white cliffs. Mean annual temperature in the Piora region is between 0 and $5^{\circ} \mathrm{C}$, with a precipitation of approximately $150 \mathrm{~cm}$ per year and an average sunlight intensity of $150 \mathrm{~W} \mathrm{~m}^{-2}$ [30]. The sampling site is characterized by the presence of a horizontal hole of about $60 \times 80 \mathrm{~cm}$ with a depth of $60 \mathrm{~cm}$. The rock surface inside the cavity is protected from direct light and rain, whereas the outside is exposed to full sunlight and weather conditions. This allowed us to obtain samples from different light regimes. Rock pieces of some millimeters to centimeters in size were split off the surface with chisel and hammer and kept in sterile Falcon tubes or petri dishes at $4^{\circ} \mathrm{C}$ in the dark until prepared for the various experiments in the laboratory.

Field Methods. Surface temperatures of rocks were obtained with an infrared reflection thermometer.

Measurement of Light Attenuation. Rock pieces of about $5 \mathrm{~cm} \times 5 \mathrm{~cm}$ in size were cut to flat plates of about $5-\mathrm{mm}$ thickness and bore holes of $8-\mathrm{mm}$ diameter, and various depths were drilled into them by using a Dremel Moto tool (Dremel, Racine, WI, USA) as described by Matthes et al. [21]. The thickness of the remaining plate was measured with a caliper (accuracy, $0.05 \mathrm{~mm}$ ). Transmitted light was measured with a PDA1 photodetector amplifier and the VIS Fiber Optic Detector (World Precision Instruments, Sarasota, FL, USA). Illumination of the rock surface by visible light was achieved either by diffuse neon light or by a beam perpendicular to the surface from a light fiber coupled to a tungsten $12-\mathrm{V}$ light source.

In Vivo Spectroscopy. Rock pieces were carefully cut rectangular to the surface, flattened with a grinding stone (Dremel Moto tool), and fixed on a mechanical positioning table such that the endolithic band was parallel to its $Y$ axis and the flattened side of the rock to be scanned was parallel to the table plane. The tip of the fiber optic coupled to the Labspec VNIR-512 diode array spectrometer (Analytical Spectral Devices, Boulder, CO, USA) and two fibers for the illumination of the rock were mounted vertically above the rock surface resulting in a light spot of about $2 \mathrm{~mm}$ in diameter. Details of the system have been described by Wiggli et al. [35]. A series of reflection spectra were collected in steps of $0.5 \mathrm{~mm}$ in a right angle across the endolithic band with an acquisition time of $8.7 \mathrm{~s}$ and a spectral resolution of $3 \mathrm{~nm}$ with a sampling interval of $1.4 \mathrm{~nm}$. Data were imported into Excel. As the noise level increased below $450 \mathrm{~nm}$ and above $750 \mathrm{~nm}$, only the data in between these values were used for calculations. The spectra were normalized at $750 \mathrm{~nm}$. A silica thin-layer chromatography plate served as white reference and a reflection spectrum obtained from a freshly cut site from a location deep in the rock was used for baseline correction. The pigment concentration was calculated for chlorophyll $a$ (Chl $a$ ) by taking the absorption at $680 \mathrm{~nm}$ directly. For bacteriochlorophyll-720 (Bchl-720) the absorption at $720 \mathrm{~nm}$ was corrected empirically for the absorption of Chl $a$ in the range between 700 and $750 \mathrm{~nm}$. The phycobilin concentration was calculated from the absorption at $620 \mathrm{~nm}$, corrected for the absorption of Chl $a$.

\section{Absorption Spectroscopy and Pigment Analyses by High-Performance Liquid Chromatography. Dolomite} rock scratched from the microbial zone was ground in a mortar and extracted with methanol or acetone $(100 \%)$. The extract was decanted and its spectrum was measured on a Uvicon 860 spectrophotometer (Kontron, Zürich, Switzerland). After sedimentation of the sandy material, the supernatant was concentrated under a nitrogen gas flow. The solution was passed through a $0.2-\mu \mathrm{m}$ particle filter and $500 \mu \mathrm{L}$ was used for highperformance liquid chromatography (HPLC) analyses on a Shimadzu 10AVP System equipped with a C-18 Grom-Sil 120 ODS-4HE reversed-phase column $(4.6 \times$ $250 \mathrm{~mm}, 5-\mu \mathrm{m}$ particle size, Stagroma, Germany) and a photo diode array detector. The flow rate was $1 \mathrm{~mL} \min ^{-1}$ at $30^{\circ} \mathrm{C}$. The solvent gradient ranged from 0 to $100 \%$ solvent $\mathrm{B}$ during the first $10 \mathrm{~min}$, then kept at $100 \%$ solvent B for additional $30 \mathrm{~min}$ [solvent A: methanol/ $\mathrm{H}_{2} \mathrm{O}$ 80:20 (v/v), solvent B: methanol/acetone $80: 20(\mathrm{v} / \mathrm{v})]$. For identification standards, Chl $a$ and Chl $b$ were purified from Scenedesmus subspicatus, and bacteriochlorophylls from Chlorobium limicola and Allochromatium warmingii.

\section{Microscopic Methods}

Light Microscopy. AWild M7binocular(Wild, Heerbrugg, Switzerland) was used for the measurements of the width and location of the bands; photographs were taken with a 


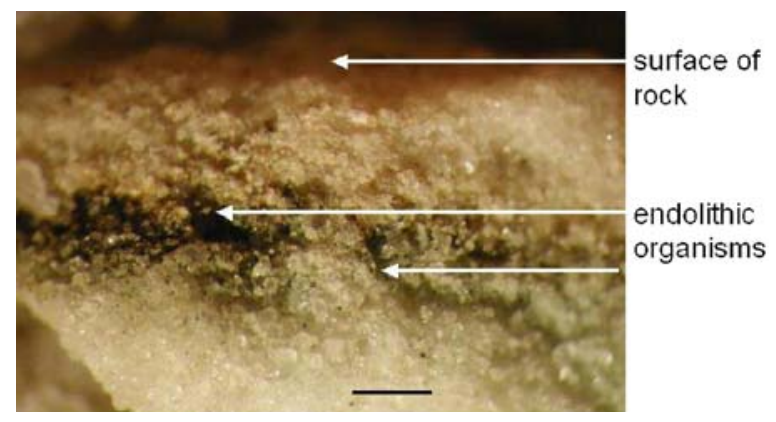

Figure 1. Macroscopic image of the endolithic layer of organisms in broken dolomite. Bar=1 mm.

Nikon Coolpix 990 digital camera and a microscope adapter (Nikon MXA 29005).

Scanning Electron Microscopy. For scanning electron microscopy (SEM), rock pieces as prepared for reflection spectroscopy were sputter-coated with gold and examined with a Sn-4100 FSEM scanning electron microscope (Hitachi, Tokyo, Japan) at $20 \mathrm{kV}$.

Laser Scanning Microscopy. CLSM and two-photon laser scanning microscopy (2P-LSM) was done with a TCS SP MP attached to an upright microscope (Leica, Heidelberg, Germany). The system was equipped with a set of lasers: argon (458, 476, 488, $514 \mathrm{~nm})$, krypton (568 $\mathrm{nm})$, helium-neon $(633 \mathrm{~nm})$, and titanium/sapphire infrared (760-900 nm). The microscope was controlled by the Leica Confocal Software Version 2.00 Build 0871 . Images were collected with $20 \times 0.5 \mathrm{NA}, 63 \times 0.9 \mathrm{NA}$ and $63 \times 1.2 \mathrm{NA}$ water-immersible lenses (Leica) in the $Z$ direction for subsequent image analyses. Images were presented as multichannel, maximum-intensity projections using the microscope software. In addition, 3-D isosurface projections were calculated by using Imaris in combination with the Surpass tool (Bitplane, Zürich, Switzerland). Rock pieces were prepared similarly as for reflection spectroscopy. Pieces of about $5 \times 5 \mathrm{~mm}$ in size were mounted on microscopy slides and studied while submersed in water. Nonspecific nucleic acid staining was carried out using DAPI (Fluka, Buchs, Switzerland), Syto 9, and Syto 40 (Molecular Probes Inc., Eugene, OR, USA). Glycoconjugates in the extracellular polymeric substances (EPS) matrix were stained with Alexa-488 (Molecular Probes) fluorescently labeled Aleuria aurantia lectin (Vector, Burlingame, CA, USA) as described previously [23].

\section{Results}

Description of Rock Material and Endolithic Organismic Bands. In exposed dolomite, endolithic microorganisms are easily observed when the rock surface is mechanically removed. These organisms form a gray to green layer a few millimeters below the rock surface (Fig. 1). The depth of the band and its thickness are variable and probably determined by the average light intensity at the specific site. From 80 samples collected randomly both from sites exposed to sunlight and from shaded ones, depth and thickness of the band were measured. Both values exhibited broad variations. However, the distance of the endolithic organisms from the surface was significantly larger $(P<0.0001)$ at sunlight-exposed sites than at shaded ones: $2.27 \pm 0.82$ and $1.01 \pm 0.51 \mathrm{~mm}$, respectively. Similarly, the width of the band was wider under high light compared to low light: $1.77 \pm 0.52$ and $1.08 \pm 0.37 \mathrm{~mm}$, respectively. Extremes for the distance from the surface for high-light sites were 0.5 and $4.8 \mathrm{~mm}$; for low light sites, 0.3 and $2.0 \mathrm{~mm}$. Besides the differences in the light regime, the temperature of rock surfaces exposed to sunlight was regularly 5 to $15^{\circ} \mathrm{C}$ above the ambient air temperature, whereas the daily fluctuations at the constantly shadowed sites were less than $5^{\circ} \mathrm{C}$.

Light Attenuation by Dolomite Rock. Figure 2 summarizes the light attenuation in visually homogeneous dolomite rock. The data points fit to an exponential curve, which, however, does not extrapolate to $100 \%$. Light entering perpendicular to the rock surface penetrated deeper into the rock as compared to diffuse light where

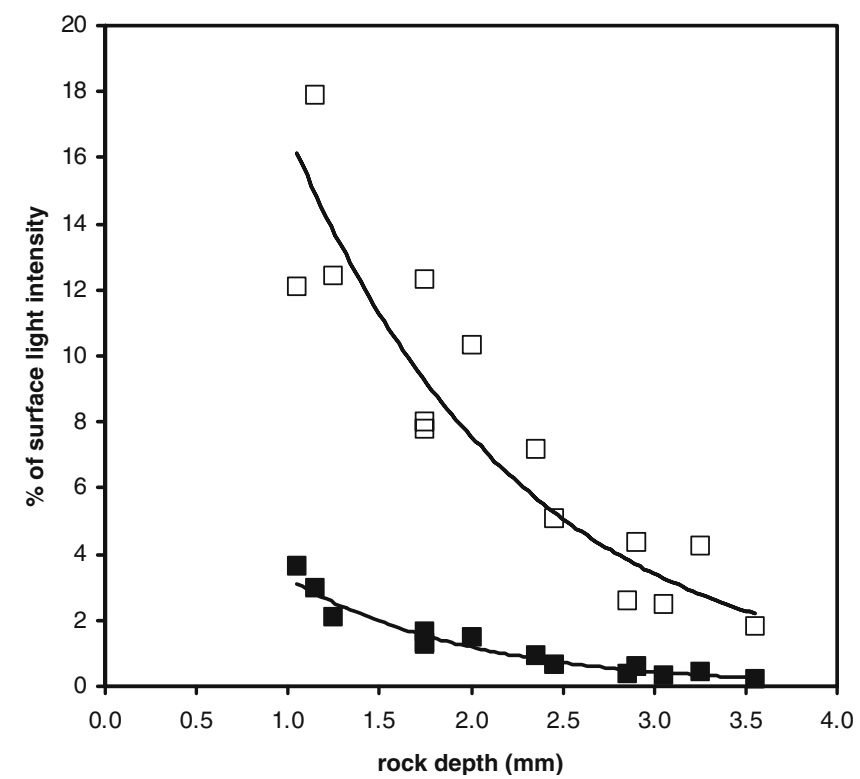

Figure 2. Light attenuation by dolomite rock in percent of surface light intensity. Open squares, illumination with perpendicularly oriented light from fiber optic $1 \mathrm{~cm}$ away from the rock surface. Closed squares, illumination with diffuse light from 2-m distant fluorescent tubes. 


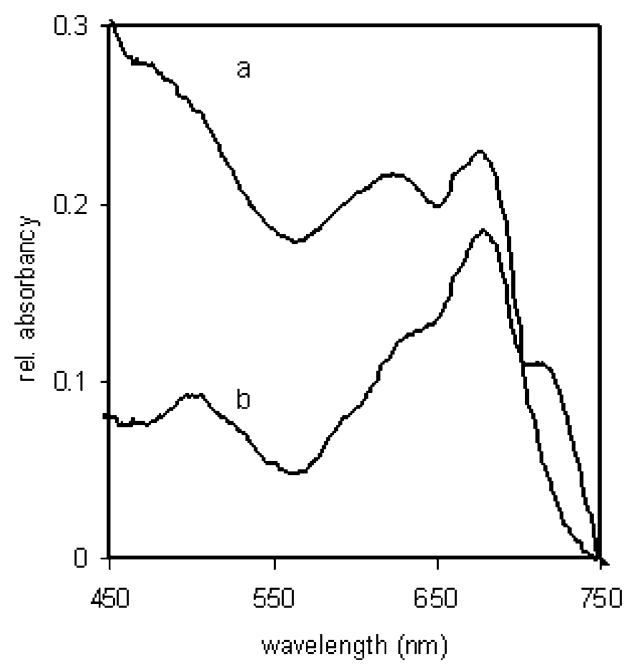

Figure 3. Examples of in vivo reflection spectra from the center of endolithic bands. (a) Site with high phycobilin content but no Bchl 720. (b) Site with low phycobilin content but with Bchl 720.

less than $5 \%$ of the surface intensity was measured at 1 $\mathrm{mm}$ within the rock.

Reflection Spectroscopy. Figure 3 shows two selected in vivo spectra from different samples, taken at the maximum pigment concentration within the band. Both spectra are characterized by the typical absorption regions of cyanobacterial pigments, Chl $a$ at $680 \mathrm{~nm}$ and phycobilins at around $620 \mathrm{~nm}$. In addition, spectrum (b) has a distinct shoulder at about $720 \mathrm{~nm}$, suggesting the presence of a bacteriochlorophyll typical for green phototrophs.

The pigment distribution across the endolithic band was determined from a set of spectra taken at intervals of $0.5 \mathrm{~mm}$ from the surface, using the calculations for Chl $a$, phycobilins and Bchl-720 as described in "Methods." When repeated at the same site, the reflection spectra were fully reproducible. In contrast, scanning at other places of the same band or moving along the direction of the band parallel to the surface resulted in a substantial pigment microheterogeneity, which was not expected at first. Especially, the size of the $720-\mathrm{nm}$ absorbing shoulder and the relative amount of phycobilins were highly variable. Figure 4 presents the distribution of the pigments across the endolithic layer for two different sites. Most pigment transects showed two peaks in Chl $a$ concentration across the band. Highlight samples normally lacked the absorption at $720 \mathrm{~nm}$ (Fig. 4a). Inside the rock, the phycobilin to chlorophyll ratio increased with depth (Fig. 4a). When present, the Bchl-720 band was situated deep in the rock coinciding with the second peak of $\mathrm{Chl} a$; phycobilins were scarce at these sites (Fig. 4b). Often, a peak at $660 \mathrm{~nm}$ was present at the outer side of the endolithic band, suggesting the presence of free chlorophyll in denatured cells (see Fig. 3a).

Pigment Analyses. The absorption spectrum of an extract of the endolithic band in methanol shows the properties of the dominating Chl $a$ with maxima at around 436 and $664 \mathrm{~nm}$. No absorption was observed above $700 \mathrm{~nm}$; thus, organisms containing Bchl $a$ or $b$ may only be present in minor quantities. A third maximum at around $467 \mathrm{~nm}$ possibly originated from other pigmented organisms in the bacterial layer (Fig. 5a). Separation of the lipophilic compounds by HPLC yielded a sum of absorption spectra, some of which were identified. A compound with $\lambda_{\max }$ of $387 \mathrm{~nm}$ eluted early (Fig. 5b); it showed a high absorption, and its spectrum suggested a scytonemin-like UV-shielding pigment [12]. Several carotenoids with the typical three absorption maxima followed (example in Fig. 5c), as well as an unknown compound with a broad band between 450 and $500 \mathrm{~nm}$ without specific structures (Fig. 5d). A compound with maxima at 466 and $650 \mathrm{~nm}$ (Fig. 5f), indicating Chl $b$, appeared after $23.3 \mathrm{~min}$. Finally, Chl $a$ eluted after $28 \mathrm{~min}$ in high concentration (Fig. 5h). Two spectra were obtained with chlorophylllike absorption properties, both with defined absorption bands at or above $700 \mathrm{~nm}$ (Figs. 5e, g), the former indicative for Bchl $a$.
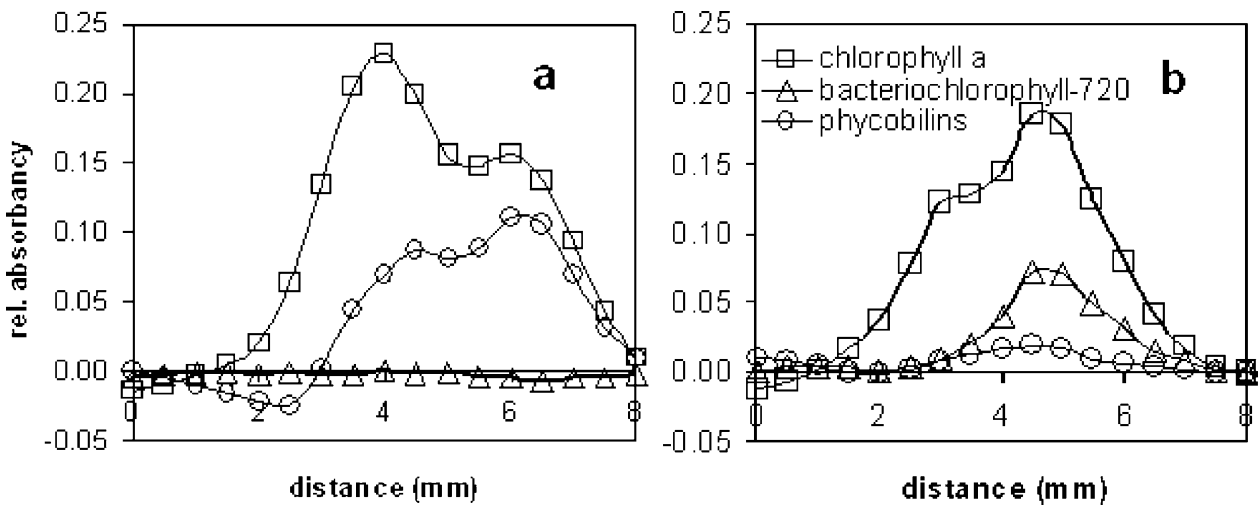

Figure 4. Pigment profiles through endolithic bands given as absorption values calculated from the reflection spectra. (a) Site with high phycobilin content but no Bchl 720. (b) Site with low phycobilin content but with Bchl 720 . 
Microscopy. SEM images allow one to describe morphotypes and to estimate roughly the dimensions of the structures, but not to get information on the spatial organization of the organisms within the band. Three selected images illustrate bacterial colonization in the dolomite. Figure 6a shows a wide distribution of single coccoid cells of about $5 \mu \mathrm{m}$ in diameter attached to surfaces, Small globules $(<0.5 \mu \mathrm{m})$ forming aggregates cover grains of rock, and fine filamentous structures of 0.3 to $0.5 \mu \mathrm{m}$ in width, lead to a network in the crevices of the rock (Fig. 6b). In Fig. 6c, large spherical cells of about 5 to $7 \mu \mathrm{m}$ in diameter are observed that seem to grow by budding. Traces of interactions between living organisms and inorganic surfaces, such as biocorrosion or calcite formation, were not observed.

CLSM (one-photon excitation) was used for imaging in the reflection and fluorescence mode. The reflection mode allowed recording of reflective signals originating from inorganic solid material, e.g., rock compounds or precipitates (see Figs. 7, 8, 9). The fluorescence mode was used directly without staining to record the autofluorescence of the organisms. For this purpose, the samples were excited with three laser lines $(488,568$, and $633 \mathrm{~nm})$ and the resulting emission signals were recorded in the green $(500-550 \mathrm{~nm})$, red $(575-625 \mathrm{~nm})$ and far red (650-800 nm) channel. Thereby, the autofluorescence of phycobilins is detected in the red channel, whereas the Chl $a$ signal is recorded in the far-red channel. The fluorescence mode was also used after staining with nucleic-acid-specific fluorochromes and glycoconjugatespecific lectins labeled with Alexa-488. LSM with twophoton excitation was used to confirm the results from one-photon excitation and to take advantage of imaging deep regions of the samples.

At low magnification, five CLSM images were taken perpendicular to the surface to form a cross section, showing again the spatial heterogeneity of the phototrophs (Fig. 7). The autofluorescence was quantified to demonstrate the distribution of both Chl $a$ and the colocalized signal of cyanobacterial pigments. The result showed a high Chl a signal in the outer region of the rock, whereas the cyanobacterial signal in this sample was highest at about $6 \mathrm{~mm}$ depth. Both signals decreased with depth corresponding to the measurement of light intensity within dolomite rock (Fig. 7).

Coccoid cyanobacteria were present not only as single cells, but also as multicellular aggregates. The size of single cells varied between 3 to $6 \mu \mathrm{m}$ in diameter. At other locations, spherical, baglike structures of 15 to $30 \mu \mathrm{m}$ in size were found (Fig. 8). Some of them clearly contained cyanobacterial cells identified by the colocalized autofluorescence (Figs. 8a, b). Other spheres contained particles of cell size but emitting a green autofluorescence (Figs. 8a, c). The sheaths around the spheres with cyanobacterial cells and green particles emitted a green autofluorescence as well. This result was obtained after one-photon excitation at $488 \mathrm{~nm}$, emission channel set to $500-550 \mathrm{~nm}$ (Figs. 8a-c), as well as by two-photon excitation at $800 \mathrm{~nm}$, emission channel set to $400-575 \mathrm{~nm}$ (Figs. 8d, e).

At certain locations, bundles of flexible filaments were observed having an autofluorescence signal similar to the coccoid cyanobacteria (Fig. 9a). Even at higher magnification the filaments did not show any structural details and no further taxonomical determination was possible.

Experiments with the life nucleic acid stains Syto 9 (one-photon excitation) and Syto 40 (two-photon excitation) at first did not show an extended heterotrophic bacterial community. These organisms only became visible as tiny spheres when the maximum-intensity projected series (shown in Fig. 9b) was examined layer by layer. Furthermore, two-photon imaging was used in combination with DAPI nucleic acid staining. The result showed the autofluorescence of the cyanobacteria within the bag as well as a DAPI signal inside the cyanobacterial cells (Figs. 8e and 9c). Due to the channel settings for recording the emission signals, the green autofluorescence of the sheath material is picked up in the same channel as the DAPI signal and therefore is imaged in the same color (green).

The application of lectins allowed imaging of glycoconjugates associated with the endolithic phototrophs (Fig. 9c). The lectin of Aleuria aurantia bound to matrix polymers in which the phototrophic cells were embedded. Interestingly, not all phototrophic cells, even of similar morphology, reacted with the lectin, indicating different cyanobacterial strains with matrix polymers of different lectin-binding properties (Fig. 9c). Isosurface presentation shows the 3-D arrangement of phototrophic cells within the glycoconjugates (Fig. 10).

\section{Discussion}

Bare dolomite rocks in the Piora Valley are ideal sites for the study of endolithic microbial systems. Phototrophic microorganisms easily penetrate porous dolomite and are observed as a distinct brown-gray to green endolithic band some millimeters below the rock surface when the surface is split off. Microbial life at these sites is limited by environmental factors such as desiccation and lack of water for long periods, a large span of fluctuating temperatures including freeze-thaw cycles, scarce nutrient availability, and variable high photosynthetic active radiation (PAR) intensity combined with a large UV-B (290-320 nm) fraction at the rock surface [26]. Such conditions are similar to extreme environments found in the Arctic and Antarctic, where endolithic organisms form one of the few ecosystems $[5,6]$. These environments have also been suggested as possible analogs for living conditions on Mars [20, 22]. 

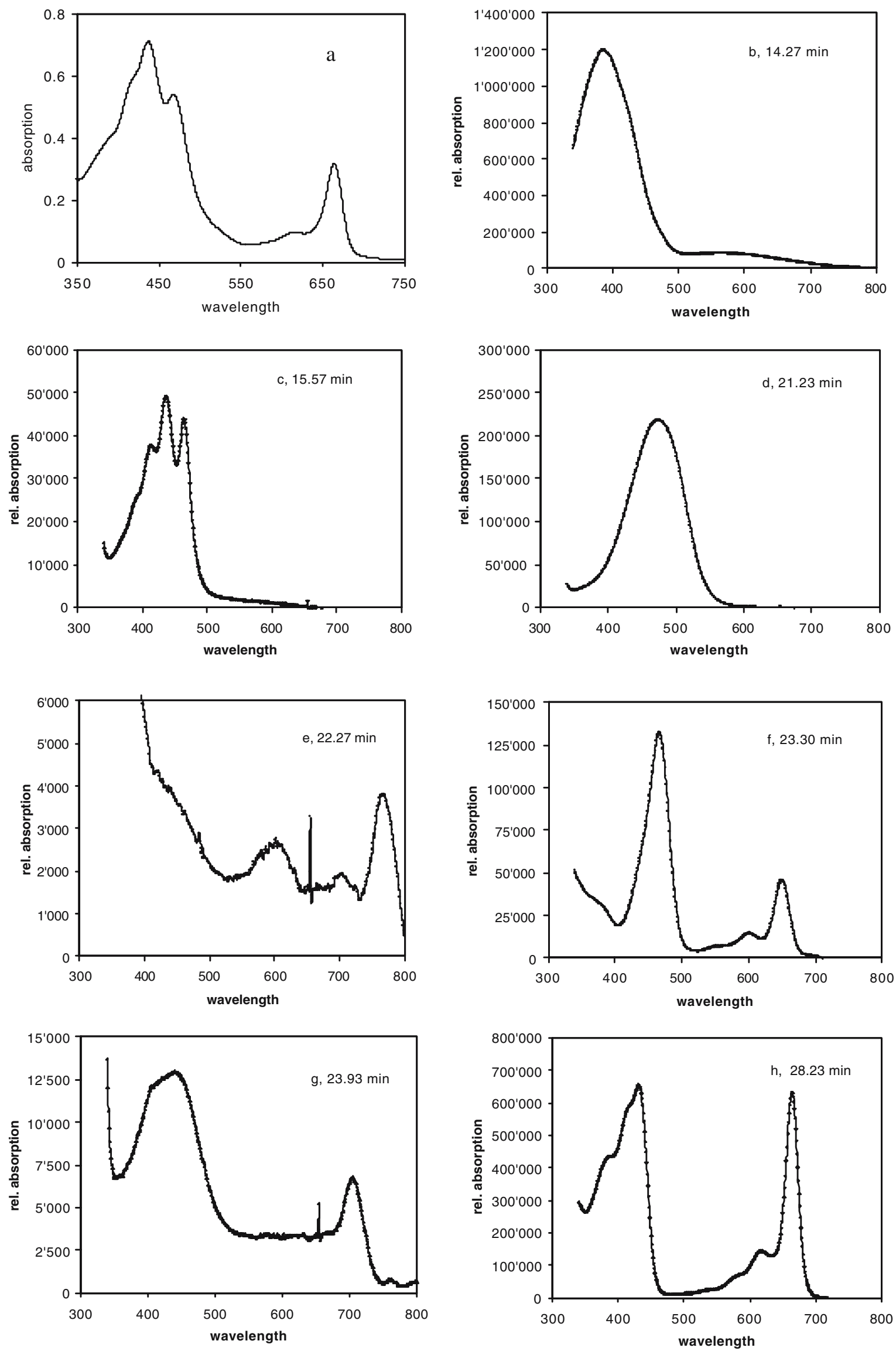
Physical Properties of the Environment. Light penetration into the rock clearly depends on the angle incident to the surface (Fig. 2). When entering perpendicular to the surface, up to $5 \%$ of the surface intensity is still available for photosynthesis at 2 to $3 \mathrm{~mm}$ depth within the rock, which compares well with the depth at which the endolithic band is found at brightlight sites. In diffuse illumination, light intensity drops more rapidly with depth. Similar data have been reported by Diels [7], whereas light intensities for the Niagara cliffs are more comparable to shadowed dolomite rock [21]. The phototrophic band in the dolomite rock has a clear inner boundary, suggesting that a specific environmental factor limits further penetration of the organisms into the rock. Jaag [19] suggested that the cyanobacteria are limited by the decreasing water availability with depth. The variable position of the cyanobacteria according to the mean light intensity (Fig. 2) rather suggests that the limiting factor is more likely the light intensity.

Composition of the Community from Spectral Studies. From microscopy studies [e.g., 1, 5, 19, 30, $34,38]$, it is obvious that the major primary producers in endolithic biofilms are cyanobacteria. Cyanobacteria are known to be well adapted to conditions of high environmental stress $[14,17,38]$ and thus are the prevalent primary producers in such conditions. The fundamental study of Jaag [19] on algal vegetation on bare rocks in Switzerland lists 210 species of mainly epi- but also endolithic phototrophic microorganisms, with 48.6\% belonging to the cyanobacteria. This dominance is demonstrated in our samples in the reflection spectra (Fig. 3), which indicate the presence of oxygenic phototrophs containing Chl $a$ and varying amounts of the accessory phycobilins. In some samples, a third pigment with an absorption maximum at about $720 \mathrm{~nm}$ was observed. The distinct shoulder at $720 \mathrm{~nm}$ observed at some low-light sites (Fig. 3b) indicates the presence of a probably new bacteriochlorophyll. Of the bacteriochlorophylls known, Bchl $e$ and certain forms of Bchl $d$ exhibit an absorption in this region [2]. This is supported by the spectrum of the methanolic extract of rock material and by selected spectra obtained after HPLC separation (Fig. 5). The peak in the raw extract at about $664 \mathrm{~nm}$ (Fig. 5a) is interpreted as the sum of Chl $a$, Chl $b$, and a bacteriochlorophyll type $d$ or $e$. As the long-wavelength peaks of these pigments overlap, the exact pigment composition can only be determined after chromatographic separation. HPLC separation gave evidence for various unidentified carotenoids and several chlorophyll-like absorbing compounds. The dominance

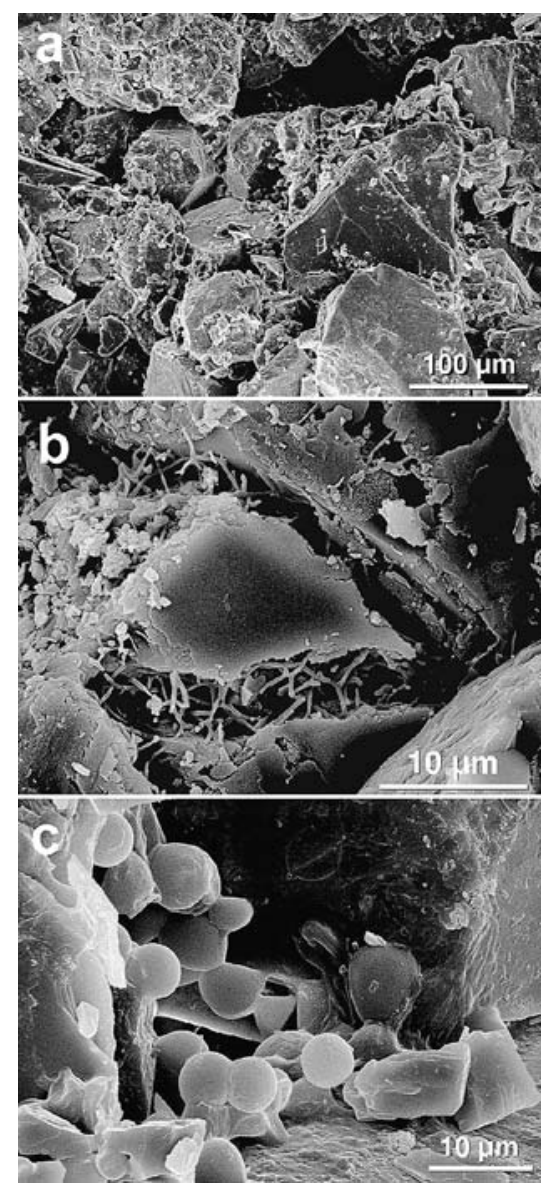

Figure 6. SEM images from endolithic organismic zone. (a) Lowmagnification overview showing single coccoid cells. (b) High magnification showing filamentous cells. (c) High magnification showing budding-like structures.

of Chl a (Fig. 5h) from the cyanobacteria had to be expected; Chl $b$ (Fig. 5f) had about $20 \%$ absorption of $\mathrm{Chl} a$. However, the absorption at $466 \mathrm{~nm}$ could also suggest the presence of a bacteriochlorophyll from green bacteria $[11,18]$. In low concentration with an absorption strength of a few percent of Chl $a$, a so far undescribed chlorophyll-like pigment was present with absorption maxima of 440 and $706 \mathrm{~nm}$ (Fig. 5g). As the pigment observed by reflection spectroscopy absorbing in vivo at $720 \mathrm{~nm}$ was not frequently seen, the one given in Fig. $5 \mathrm{~g}$ might be the same. The spectrum in Fig. 5e with a main band at $770 \mathrm{~nm}$ suggests the presence of a very small population of phototrophic bacteria containing Bchl $a$ [18].

Phycobilins as markers of cyanobacteria were less dominant in samples showing the 720-nm absorption (Fig. 3b vs a). The dominance of oxygenic phototrophs was imaged in previous results from enrichment cultures with endolithic material as inoculum, where growth of

Figure 5. Absorption spectra of the raw methanolic extract of endolithic rock material (a) and of selected compounds after HPLC separation $(b-h)$. Numbers given indicate the time of appearance during chromatography. 
the green algae Stichococcus and Chlorella spp. and of the cyanobacteria Nostoc and Calothrix spp. was observed [30]. Sequence data suggested a range of cyanobacteria, including relatives of Leptolyngbya, Scytonema, Microcoleus, Chrooccidiopsis, and Anabaena. Interestingly the most dominant genus in the studies of Jaag [19], the coccoid Gloeocapsa (sanguinea and Kützingiana), was not detected by molecular means [30].

\section{Localization of the Microbial Community by} Spectroscopy. Spectroscopy allowed differentiation between eukaryotic algae and cyanobacteria based on the presence of phycobilins. A profile of the photosynthetic pigments across the endolithic band suggested

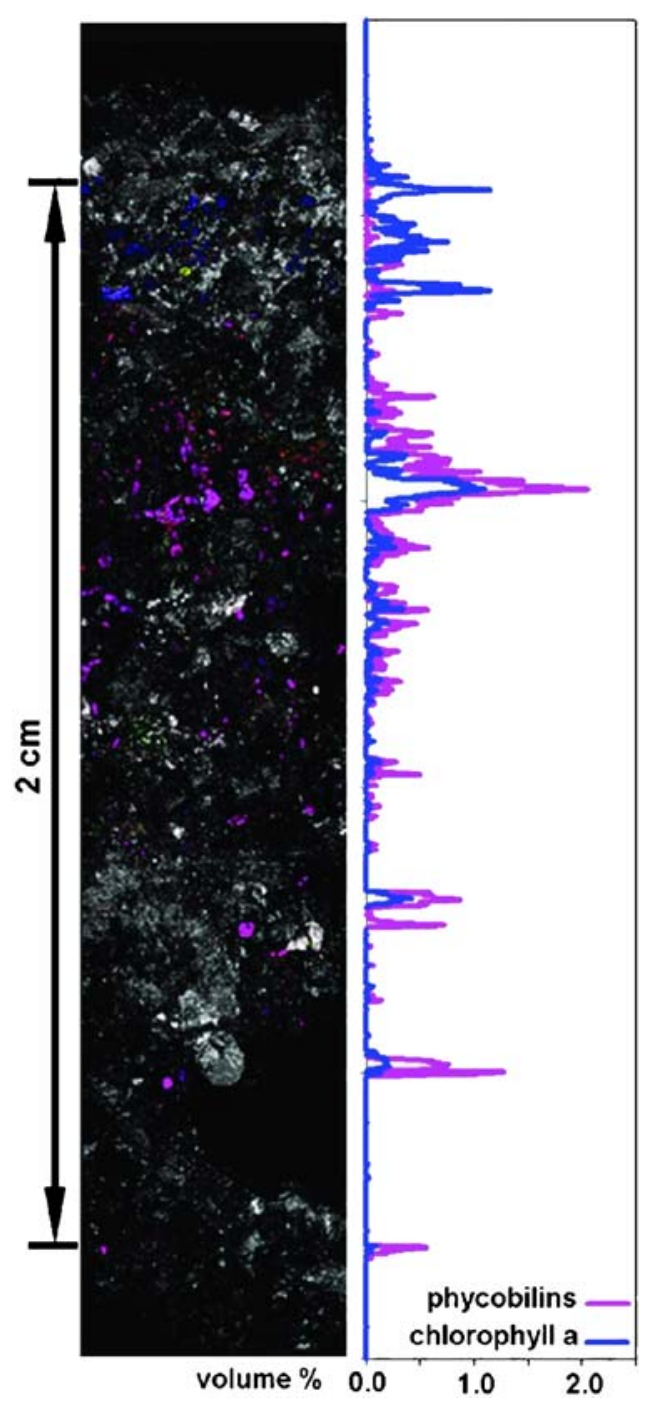

Figure 7. CSLM profile through outer part of dolomite rock with endolithic zone of phototrophic microorganisms and quantification of the autofluorescence signals. The image is composed of five single image series. Volumes were calculated from each of the five image stacks corresponding to the various depths. Color allocation: reflection, white; Chl $a$, blue; phycobilins, pink.
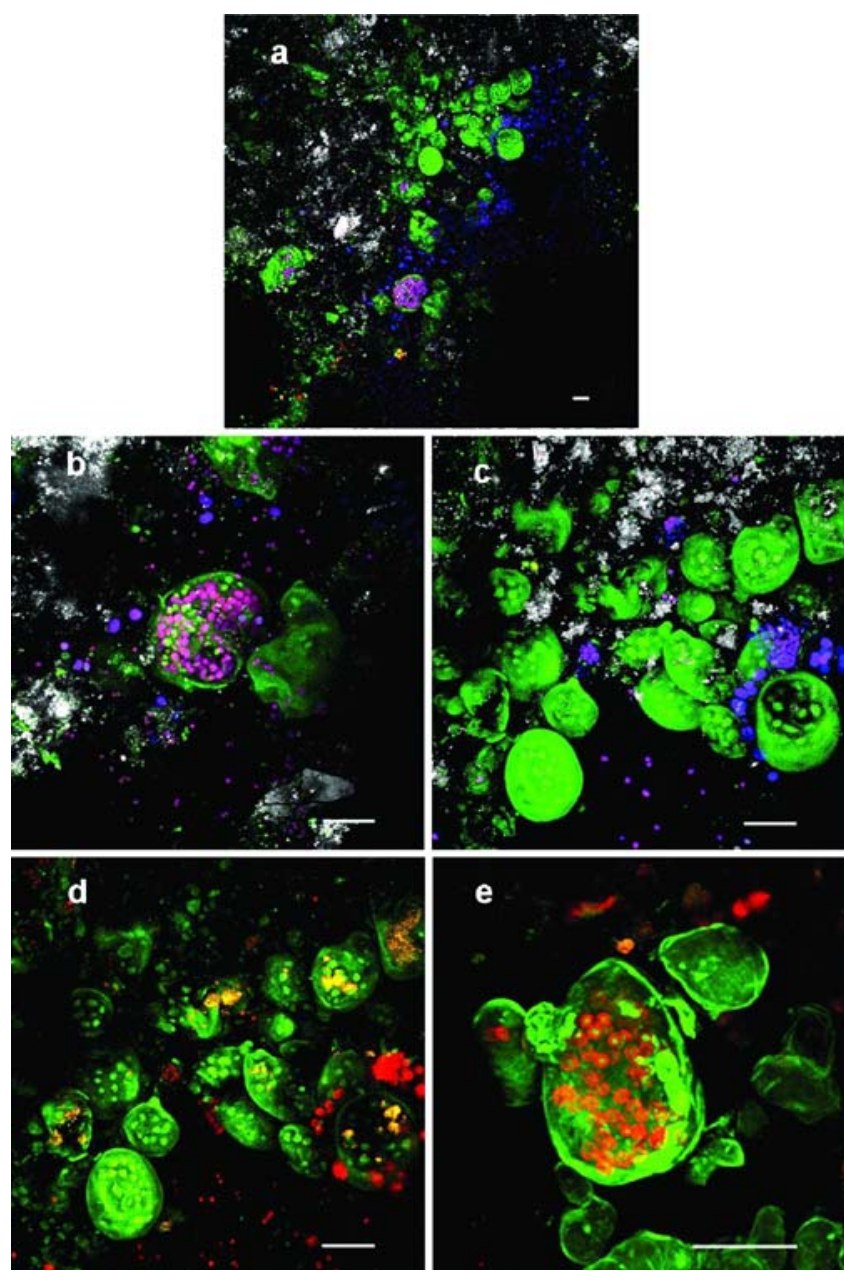

Figure 8. Maximum intensity projection of LSM images from endolithic microbial community showing locations with baglike structures (bars $=20 \mu \mathrm{m}$ ). (a) One-photon LSM after excitation with three visible lasers and record of signals in four channels. Color allocation: reflection from minerals, white; unknown green autofluorescence, green; colocalized autofluorescence of cyanobacteria in the red and far-red channel, pink (red/blue); autofluorescence of Chl $a$ in the far-red channel, blue. (b) Detail of image (a) at higher magnification with pink microcolony surrounded by a distinct envelope showing green autofluorescence. Color allocation as in (a). (c) Detail of image (a) at higher magnification with single blue coccoid cells and green microcolonies surrounded by a distinct envelope showing also a green autofluorescence. Color allocation as in (a). (d) Two-photon LSM of baglike structures with excitation at $800 \mathrm{~nm}$ and dual-channel recording of autofluorescence (green emission, 400-575 nm; red emission, 600-750 nm). (e) Two-photon LSM of baglike structures with excitation at $800 \mathrm{~nm}$ and dual-channel recording of autofluorescence and DAPI staining (green emission, 400-550 nm; red emission, 600-750 nm). DAPI stained the cell interior of the cyanobacteria within the baglike structure only, whereas the other green signal corresponds to the green autofluorescence of the envelope material. 

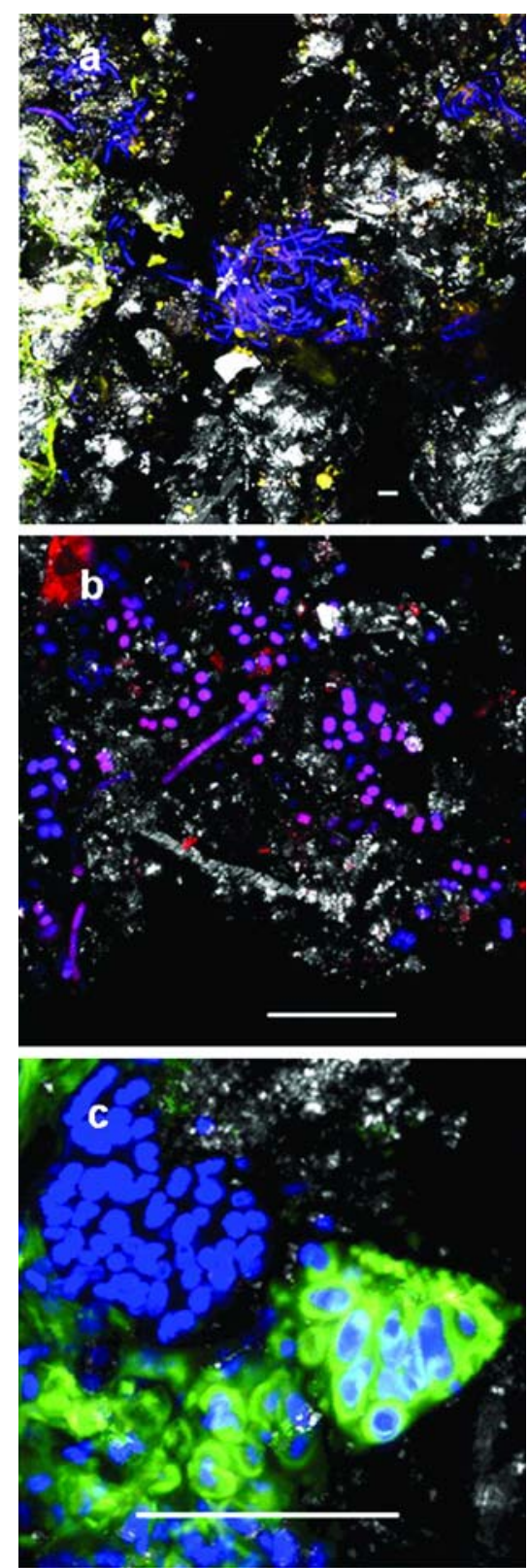

Figure 9. Maximum intensity projection of CLSM images from endolithic microbial community showing locations with different cell types and EPS glycoconjugates. Color allocation: reflection from minerals, white; colocalized autofluorescence of cyanobacteria in the red and far-red channel, pink/red/blue (bar=20 $\mu \mathrm{m})$. (a) Overview showing mineral reflection and autofluorescence of a microcolony with bent filamentous phototrophic cells. (b) Location with autofluorescence of coccoid and straight filamentous phototrophic cells. Sample was also stained by a live nucleic-acidspecific stain. Color allocation of Syto9, green. (c) Phototrophic microcolony after lectin staining showing cell clusters with and without glycoconjugate production. Color allocation of lectin, green.

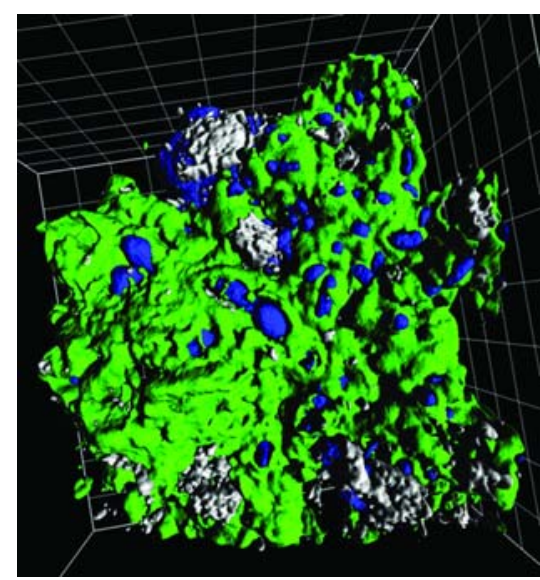

Figure 10. Three-channel isosurface presentation of an endolithic phototrophic microcolony with associated glycoconjugates. Most of the phototrophic cells (blue) attached to mineral surfaces (white) are deeply embedded in a glycoconjugate layer visualized by lectin staining (green) (grid size $=20 \mu \mathrm{m}$ ).

that eukaryotic green algae are located closer to the surface, whereas the cyanobacteria are found in deeper zones (Fig. 4a), which was confirmed by quantitative image analysis of CLSM cross sections (Fig. 7). In cyanobacteria, the ratio between chlorophyll and the accessory phycobilins is indicative of chromatic adaptation. Indeed, the phycobilins increased in relation to the chlorophyll with depth (Fig. 4a). Similar observations were reported by Quesada et al. [28] in arctic samples.

Both trans-sections in Fig. 4 exhibited distinct peaks in the distribution of the pigments, indicating that the phototrophs in the endolithic layer are spatially ordered. Similar structures in endolithic systems were also described by Russel et al. [29] from the Antarctica, using FT-Raman spectroscopy. These authors point to differences observed between different sampling sites, which were some kilometers apart. In contrast, our measurements with optical tracing give evidence of a spatial microheterogeneity in the millimeter to centimeter range. Our data fit well with the model suggested by Pohl [27] for euendolithic biofilms in carbonate rocks with three major zones. On the outer side of the active layer of photobionts is a zone of partially dead and decaying cells; indeed, we often observed a reddish band [30] as well as absorption at $660 \mathrm{~nm}$, which is indicative for free or denatured chlorophylls. According to Jaag [19], Gloeocapsa sp. were the most frequent cyanobacteria in rock, carrying a red or violet gelatinous envelope of variable thickness. In fact, a reflection spectrum of such "red" dolomite (data not shown) yielded a similar spectrum as given by Jaag [19].

Localization of the Microbial Community by Microscopic Methods. LSM is an excellent technique to visualize in situ microbial communities at interfaces 
and in complex matrices and is thus the tool of choice in biofilm research [24]. The technique was already employed for imaging phototrophic microbial biofilms and mats in various habitats $[32,36]$. This approach can be taken a step further by using one-photon and twophoton LSM as a tool for imaging, differentiation, and quantification of phototrophic microorganisms within microbial biofilms [25]. It was also applied in the present study. The LSM results of Piora dolomite showed different cyanobacterial coccoid morphotypes. Confocal images revealed predominantly coccoid organisms with bright phycobilin autofluorescence, this morphotype seems also to be typical for dry limestones, which only temporarily get wet [16]. Most cells were present in microcolonies; some of these were covered by a thick layer of glycoconjugates and embedded as densely packed microcolonies in a thin envelope. Surprisingly, the envelope became visible without staining due to its green autofluorescence. The microcolonies within the envelope had either the known colocalized cyanobacterial pink signal or a green autofluorescence similar to the one of the envelope. This green autofluorescence has not been seen in liquid cultures prepared from endolithic material (data not shown). Furthermore, the green autofluorescence from one-photon excitation $(488 \mathrm{~nm})$ was confirmed by two-photon excitation LSM (Figs. 8a-c compared to $\mathrm{d}$ and $\mathrm{e})$. This finding remains unclear and needs more investigation. Staining with a fluorescent lectin reveals strong binding toward the glycoconjugates of some cyanobacterial strains (Figs. 9e, f). Yet, in order to stain a greater proportion of the cyanobacterial glycoconjugates, a screening for specific lectins, as suggested by Staudt et al. [33], would be necessary. In Fig. 10, the 3D structure of the three components becomes visualized, the cells in blue, the surrounding EPS in green, and the rock material in white-gray. Cells are embedded in the polymer matrix, which fully fills out the pore space.

Physiological Adaptation to the Environment . Cyanobacteria as evolutionarily ancient organisms may contain UV-shielding pigments, scytonemins, and mycosporine-like amino acids (MAAs) $[8,13]$. One compound after HPLC separation (Fig. 5b) is indicative for scytonemins $[3,12]$; this peak has a large absorption of about twice the value of Chl $a$. The biosynthesis of such compounds is not only induced by UV illumination, but other harsh environmental factors, such as temperature and osmotic or photooxidative stress, may also act synergistically and enhance the accumulation of UV-protecting compounds [4]. Garcia-Pichel and Castenholz [13] found scytonemin extracellularly in the sheaths of colonies and cells. After irradiation with UV-B, Nostoc produced MAAs absorbing at $335 \mathrm{~nm}$ [9]. These substances exhibit fluorescence with an emission in the blue region at $436 \mathrm{~nm}$ [31]. However, as these compounds absorb in the UV they are not detected by reflection spectroscopy but possibly with UV or two-photon excitation LSM (Figs. 8d, e).

Interestingly, irradiation of Nostoc with UV-B not only stimulated the formation of MAAs but also increased the dry weight of cells two- to threefold due to glycan formation, which was deposited as sheath material [9]. The large volume of EPS relative to that of the enclosed cells in the endolithic band may indicate the stress situation in this dolomite rock environment.

Heterogeneity of the Distribution of the Organisms within the Endolithic Band. Although observed by the naked eye the endolithic band looks homogeneous and continuously following a line a few millimeters below the rock surface, a minor magnification (Fig. 1) demonstrates that the dimensions of the band are variable and the distribution of the cells within the band very heterogeneous. This is especially clear in the CLSM cross section (Fig. 7) with local accumulations of packed cells. Deeper inside the rock, single cells still exist. This heterogeneity is not seen in the reflection spectra cross sections, as this technique has not the necessary spatial resolution and averages over distances of about $0.5 \mathrm{~mm}$. Still, large differences in pigment reflection intensity were found between different sites of the same sample. Furthermore, the depth of the band and its size show a broad variation, e.g., at a high-light site $2.27 \pm$ $0.82 \mathrm{~mm}(\mathrm{SD})$ as mean depth, with extremes of 0.5 and $4.8 \mathrm{~mm}$. This can hardly be explained by the light regime. Weathered dolomite is heterogeneous concerning its porosity, which controls the water availability of the cells. Unfortunately, microelectrodes cannot solve such questions in rock material. Organisms with an absorption at $720 \mathrm{~nm}$ are restricted to shaded sites and there located toward the inside of the band, they seem to be less stress tolerant toward light and temperature.

\section{Conclusion}

The study using different methods demonstrated a heterogeneous distribution of the cells and the specific pigments as markers of phototrophic organisms in the endolithic band. It also suggested multiple survival strategies of the endolithic population. Besides being buried within the rock, the cells protect themselves from intense light and UV by producing UV-shielding pigments that become deposited in the exopolymers and may be the cause of the green autofluorescent spheres and envelopes surrounding the cyanobacterial microcolonies (Fig. 8). The massive extracellular polymeric substances in the form of glycoconjugates may also protect the cells from dehydration (Figs. 9c and 10), adsorb water and nutrients, and recycle the latter within the living endolithic microbial community. Both func- 
tions make sure that the cyanobacterial cells survive extended periods of drought.

It will be of high interest to obtain information on the heterotrophic community accompanying the primary producers.

\section{Acknowledgments}

We thank Drs. F. Schanz and M. Wiggli for fruitful discussions, the help concerning statistical calculations, and treatment of the in vivo spectra. We are much indebted to Dr. B. Wise for his help in clarifying the English text and Dr. J. Blom for the HPLC analyses. The excellent technical assistance of U. Kuhlicke (LSM) and U. Jauch (SEM) is appreciated.

\section{References}

1. Bell, RA (1993) Cryptoendolithic algae of hot semiarid lands and deserts. J Phycol 29: 133-139

2. Borrego, CM, Garcia-Gil, J, Cristina, XP, Vila, X, Abella, CA (1998) Occurrence of new bacteriochlorophyll $d$ forms in natural populations of green photosynthetic sulfur bacteria. FEMS Microbiol Ecol 26: 257-267

3. Bultel-Poncé, V, Felix-Theodose, F, Sarthou, C, Ponge, JF, Bodo, B (2004) New pigments from the terrestrial cyanobacterium Scytonema sp. collected on the Mitaraka Inselberg, French Guyana. J Nat Prod 67: 678-681

4. Cockell, CS, Knowland, J (1999) Ultraviolet radiation screening compounds. Biol Rev 74: 311-345

5. De la Torre, JR, Goebel, BM, Friedmann, EI, Pace, NR (2003) Microbial diversity of cryptoendolithic communities from the McMurdo dry valleys, Antarctica. Appl Environ Microbiol 69: 3858-3867

6. De los Rios, A, Wierzchos, J, Sancho, LG, Ascaso, C (2003) Acid microenvironments in microbial biofilms of Antarctic endolithic microecosystems. Environ Microbiol 5: 231-237

7. Diels, L (1914) Die Algen-Vegetation der Südtiroler Dolomitriffe. Ber Dtsch Bot Ges 32: 502-526

8. Dillon, JG, Tatsumi, CM, Tandingan, PG, Castenholz, RW (2002) Effect of environmental factors on the synthesis of scytonemin, a UV-screening pigment, in a cyanobacterium (Chroococcidiopsis sp.). Arch Microbiol 177: 322-331

9. Ehling-Schulz, M, Bilger, W, Scherer, S (1997) UV-B-induced synthesis of photoprotective pigments and extracellular polysaccharides in the terrestrial cyanobacterium Nostoc commune. J Bacteriol 179: 1940-1945

10. Friedmann, EI, Galun, M (1974) Desert algae, lichens and fungi. In: Brown, GWJ (Ed.) Desert Biology. Academic Press, New York, pp $165-212$

11. Frigaard, N-U, Larsen, KL, Cox, RP (1996) Spectrochromatography of photosynthetic pigments as a fingerprinting technique for microbial phototrophs. FEMS Microbiol Ecol 20: 69-77

12. Garcia-Pichel, F, Castenholz, RW (1991) Characterization and biological implications of scytonemin, a cyanobacterial sheath pigment. J Phycol 27: 395-409

13. Garcia-Pichel, F, Castenholz, RW (1993) Occurrence of UVabsorbing, mycosporine-like compounds among cyanobacterial isolates and an estimate of their screening capacity. Appl Environ Microbiol 59: 163-169

14. Garcia-Pichel, F, Belnap, J (1996) Microenvironments and microscale productivity of cyanobacterial desert crusts. J Phycol 32: 774782
15. Garcia-Pichel, F, Belnap, J, Neuer, S, Schanz, F (2003) Estimates of global cyanobacterial biomass and its distribution. Arch Hydrol Suppl Algol Studies 109: 213-228

16. Garty, J (1999) Lithobionts in the Eastern Mediterranean. In: Seckbach, J (Ed.) Enigmatic Microorganisms and Life in Extreme Environments. Kluwer Academic Publishers, Dordrecht, pp 257276

17. Grossmann, AR, Schaefer, MR, Chiang, GG, Collier, JL (1994) The responses of cyanobacteria to environmental conditions: light and nutrients. In: Briant, DA (Ed.) The Molecular Biology of Cyanobacteria. Kluwer Academic Publishers, Dordrecht, pp 641675

18. Imhoff, JF (1995) Taxonomy and physiology of phototrophic purple bacteria and green sulfur bacteria. In: Blankenship, RE, Madigan, MT, Bauer, CE (Eds.) Anoxygenic Photosynthetic Bacteria. Kluwer Academic Publishers, Dordrecht, pp 1-15

19. Jaag, O (1945) Untersuchungen über die Vegetation und Biologie der Algen des nackten Gesteins in den Alpen, im Jura und im schweizerischen Mittelland. Beitr Kryptogamenflora Schweiz 9: 1560

20. MacKay, CP (1993) Relevance of Antarctic microbial ecosystems to exobiology. In: Friedmann, EI (Ed.) Antarctic Microbiology. Wiley-Liss, New York, pp 593-601

21. Matthes, U, Turner, SJ, Larson, DW (2001) Light attenuation by limestone rock and its constraint on the depth distribution of endolithic algae and cyanobacteria. Int J Plant Sci 162: 263270

22. Nealson, K, Berelson, W (2003) Layered microbial communities and the search for life in the universe. Geomicrobiol J 20: 451462

23. Neu, ThR, Swerhone, GDW, Lawrence, JR (2001) Assessment of lectin-binding analysis for in situ detection of glycoconjugates in biofilm systems. Microbiology 147: 299-313

24. Neu, ThR, Lawrence, JR (2002) Laser scanning microscopy in combination with fluorescence techniques for biofilm study. In: Bitton, G (Ed.) The Encyclopedia of Environmental Microbiology, vol. 4. Wiley \& Sons, New York, pp 1772-1788

25. Neu, ThR, Woelfl, S, Lawrence, JR (2004) Three-dimensional differentiation of photo-autotrophic biofilm constituents by multichannel laser scanning microscopy (single-photon and twophoton excitation). J Microbiol Methods 56: 161-172

26. Pentecost, A, Whitton, BA (2000) Limestones. In: Whitton, BA, Potts, M (Eds.) The Ecology of Cyanobacteria. Kluwer Academic Publishers, Dordrecht, pp 257-279

27. Pohl, W (2000) Wechselwirkungen zwischen endolithischen Biofilmen und Karbonatgesteinen in alpinen Gebieten Mitteleuropas. Dissertation, Universität Göttingen. http://webdoc.sub.gwdg.de/ diss/2000/pohl/diss_w_pohl.pdf)

28. Quesada, A, Vincent, WF, Lean, DRS (1999) Community and pigment structure of Arctic cyanobacterial assemblages: the occurrence and distribution of UV-absorbing compounds. FEMS Microbiol Ecol 28: 315-323

29. Russell, NC, Edwards, HGM, Wynn-Williams, DD (1998) FTRaman spectroscopic analysis of endolithic microbial communities from Beacon sandstone in Victoria Land, Antarctica. Antarct Sci 10: $63-74$

30. Sigler, WV, Bachofen, R, Zeyer, J (2003) Molecular characterization of endolithic cyanobacteria inhabiting exposed dolomite in central Switzerland. Environ Microbiol 5: 618-627

31. Sinha, RP, Klisch, M, Häder, D-P (1999) Induction of a mycosporine-like amino acid (MAA) in the rice-field cyanobacterium Anabaena sp. by UV irradiation. J Photochem Photobiol B 52: 59-64

32. Sole, A, Gaju, N, Mendez-Alvarez, S, Esteve, I (2001) Confocal laser scanning microscopy as a tool to determine cyanobacteria biomass in microbial mats. J Microscopy 204: 258-262 
33. Staudt, C, Horn, H, Hempel, DC, Neu, ThR (2003) Screening of lectins for staining lectin-specific glycoconjugates in the EPS of biofilms, In: Lens, P, Moran, AP, Mahony, T, Stoodley, P, O'Flaherty, V (Eds.) Biofilms in Medicine, Industry and Environmental Biotechnology. IWA Publishing, London, pp 308-326

34. Van Thielen, N, Garbary, DJ (1999) Life in the rocks-endolithic algae. In: Seckbach, J (Ed.) Enigmatic Microorganisms and Life in Extreme Environments, Kluwer Academic Publishers, Dordrecht, pp 245-253

35. Wiggli, M, Ghosh, R, Bachofen, R (1996) Optical fiber-based in situ spectroscopy of pigmented single colonies. Appl Environ Microbiol 62: 3339-3343
36. Wiggli, M, Smallcombe, A, Bachofen, R (1999) Reflectance spectroscopy and laser confocal microscopy as tools in an ecophysiological study of microbial mats in an alpine bog pond. J Microbiol Methods 34: 173-182

37. Wynn-Williams, DD, Edwards, HGM, Garcia-Pichel, F (1999) Functional biomolecules of Antarctic stromatolitic and endolithic cyanobacterial communities. Eur J Phycol 34: 381391

38. Wynn-Williams, DD (2000) Cyanobacteria in deserts-life at the limit? In: Whitton, BA, Potts, M (Eds.) The Ecology of Cyanobacteria. Kluwer Academic Publishers, Dordrecht, pp 341-366 